\title{
Adrenergic Mechanisms Contribute to the Late Phase of Hypoglycemic Glucose Counterregulation in Humans by Stimulating Lipolysis
}

\author{
Carmine G. Fanelli, Pierpaolo De Feo, Francesca Porcellati, Gabriele Perriello, Elisabetta Torlone, \\ Fausto Santeusanio, Paolo Brunetti, and Geremia B. Bolli \\ Istituto di Medicina Interna e Scienze Endocrine e Metaboliche, Università di Perugia, 06126 Perugia, Italy
}

\begin{abstract}
Three studies were performed on nine normal volunteers to assess whether catecholamine-mediated lipolysis contributes to counterregulation to hypoglycemia. In these three studies, insulin was intravenously infused for $8 \mathrm{~h}\left(0.30 \mathrm{mU} \cdot \mathrm{kg}^{-1} \cdot \mathrm{min}^{-1}\right.$ from 0 to $180 \mathrm{~min}$, and $0.40 \mathrm{mU} \cdot \mathrm{kg}^{-1} \cdot \mathrm{min}^{-1}$ until $480 \mathrm{~min}$ ). In study I (control study), only insulin was infused; in study II (direct + indirect effects of catecholamines), propranolol and phentolamine were superimposed to insulin and exogenous glucose was infused to reproduce the same plasma glucose (PG) concentration of study I. Study III (indirect effect of catecholamines) was the same as study II, except heparin (0.2 $\mathrm{U} \cdot \mathrm{kg}^{-1} \cdot \mathrm{min}^{-1}$ after $80 \mathrm{~min}$ ), $10 \%$ Intralipid (1 $\mathrm{ml} \cdot \mathrm{min}^{-1}$ after $160 \mathrm{~min}$ ) and variable glucose to match PG of study II, were also infused. Glucose production (HGO), glucose utilization (Rd) $\left[3-{ }^{3} \mathbf{H}\right]$ glucose, and glucose oxidation and lipid oxidation (LO) (indirect calorimetry) were determined. In all three studies, $P G$ decreased from $\approx 4.8$ to $\approx 2.9 \mathrm{mmol} /$ liter $(P=\mathrm{NS}$ between studies), and plasma glycerol and FFA decreased to a nadir at $120 \mathrm{~min}$. Afterwards, in study I plasma glycerol and FFA increased by $\approx 75 \%$ at $480 \mathrm{~min}$, but in study II they remained $\approx \mathbf{4 0 \%}$ lower than in study I, whereas in study III they rebounded as in study I $(P=N S)$. In study II, LO was lower than in study $I\left(1.69 \pm 0.13 \mathrm{vs} .3 .53 \pm 0.19 \mu \mathrm{mol} \cdot \mathrm{kg}^{-1} \cdot \mathrm{min}^{-1}, P\right.$ $<0.05$ ); HGO was also lower between 60 and $480 \mathrm{~min}$ (7.48 \pm 0.57 vs. $\left.11.6 \pm 0.35 \mu \mathrm{mol} \cdot \mathrm{kg}^{-1} \cdot \mathrm{min}^{-1}, P<0.05\right)$, whereas $R d$ was greater between 210 and $480 \mathrm{~min}(19 \pm 0.38$ vs. $11.4 \pm 0.34 \mu \mathrm{mol} \cdot \mathrm{kg}^{-1} \cdot \mathrm{min}^{-1}$, respectively, $\left.P<0.05\right)$. In study III, LO increased to the values of study I; between 4 and $8 \mathrm{~h}$, HGO increased by $\approx 2.5 \mu \mathrm{mol} \cdot \mathrm{kg}^{-1} \cdot \mathrm{min}^{-1}$, and Rd decreased by $\approx 7 \mu \mathrm{mol} \cdot \mathrm{kg}^{-1} \cdot \mathrm{min}^{-1} \mathrm{vs}$. study II. We conclude that, in a late phase of hypoglycemia, the indirect effects of catecholamines (lipolysis mediated) account for at least $\approx 50 \%$ of the adrenergic contribution to increased HGO, and $\approx 85 \%$ of suppressed Rd. (J. Clin. Invest. 1992. 89:2005-2013.) Key words: catecholamines $\bullet$ norepinephrine $\bullet$ epinephrine $\bullet$ free fatty acids - glycerol
\end{abstract}

Address correspondence to Geremia B. Bolli, M.D., Istituto Medicina Interna e Scienze Endocrine e Metaboliche, Via E. Dal Pozzo, I-06126 Perugia, Italy.

Received for publication 2 April 1991 and in revised form $17 \mathrm{De}$ cember 1991.

J. Clin. Invest.

(C) The American Society for Clinical Investigation, Inc.

0021-9738/92/06/2005/09 \$2.00

Volume 89, June 1992, 2005-2013

\section{Introduction}

The physiological mechanisms of glucose counterregulation have recently been studied in a model of moderate but prolonged hypoglycemia induced by a continuous, low dose infusion of insulin (1-6). This model of prolonged hypoglycemia is relevant to the clinical situation of hypoglycemia in patients with insulinoma (7), and patients with diabetes mellitus treated either with insulin $(8,9)$ or sulphonylureas $(10)$.

It has been concluded from these studies (11) that in an early phase, glucose counterregulation involves: first, suppression of endogenous insulin secretion, and second, an early but sustained increase in hepatic glucose production, the first two lines of defense against hypoglycemia (1). In a later phase, the third line of defense, suppression of glucose utilization, becomes an important mechanism in preventing a more severe hypoglycemia (1). All counterregulatory hormones, glucagon and adrenaline (rapid hormones) $(5,6)$, as well as growth hormone and cortisol (slow hormones) $(3,4,12)$ contribute to counterregulation, although in different phases and with different mechanisms (11).

In response to insulin-induced hypoglycemia, after initial suppression, plasma FFA, glycerol, and ketone bodies, all rebound above basal levels, whereas plasma alanine decreases with no changes in plasma lactate concentration (1). In theory, changes in one or more of these substrates may contribute to glucose counterregulation. For example, release of lactate, alanine, glycerol, and free fatty acids from peripheral tissues to the liver might sustain gluconeogenesis, the predominant, if not the exclusive, source of glucose produced by the liver during prolonged hypoglycemia (13). In addition, the increase in plasma FFA might suppress peripheral glucose utilization by a mechanism of substrate competition in insulin-sensitive tissues $(14,15)$, and finally, the increase in plasma ketone bodies might provide an alternative fuel for oxidation by the brain, thus minimizing the effects of neuroglycopenia $(16,17)$.

Caprio et al. (18) did not find a counterregulatory role of the increase in plasma FFA mediated by adrenergic mechanism during insulin-induced hypoglycemia. However, it is likely that in the Caprio et al. studies (18) only a partial, not a total, adrenergic blockade was achieved, and the unblocked adrenergic effects masqueraded the potential counterregulatory contribution of lipolysis during hypoglycemia.

The present series of studies were undertaken to test the hypothesis that catecholamine-mediated lipolysis plays a physiological role in counterregulation to prolonged insulin hypoglycemia in man. For this purpose, glucose counterregulation was examined in a group of healthy subjects in a model of prolonged hypoglycemia $(1,13)$, either during suppression or replacement of the increases in plasma glycerol and FFA which 
occurs after $\approx 2-2.5 \mathrm{~h}$ of hypoglycemia (1). Our results indicate that in a late phase of hypoglycemia, catecholamine-mediated lipolysis contributes to both increased hepatic glucose production and suppressed glucose utilization, thus playing an important counterregulatory role in the prevention of severe hypoglycemia.

\section{Methods}

Subjects. Informed consent was obtained from nine healthy volunteers (six males and three females) aged $25 \pm 1$ yr, all within $10 \%$ of their ideal body weight (101 $\pm 2 \%$, Metropolitan Life Insurance Tables) with no family history of diabetes mellitus or endocrine diseases. For three days before the studies all subjects consumed a weight-maintenance diet containing at least $250 \mathrm{~g}$ carbohydrate.

Protocol. Institutional Review Board approval was obtained for these studies. All subjects were admitted to the Clinical Research Center of the Istituto di Medicina Interna e Scienze Endocrine e Metaboliche, University of Perugia, between 6:30 and 7:00 a.m., after fasting overnight $(9-10 \mathrm{~h})$. They were placed at bed rest and maintained in the supine position throughout experiments. To obtain arterialized-venous blood samples (19), a hand vein was cannulated in a retrograde position with a 21-gauge butterfly needle, with the hand maintained at $60-65^{\circ} \mathrm{C}$ in a thermoregulated Plexiglas box. An antecubital vein of the contralateral arm was cannulated with an 18-gauge catheter and used for primed $(22 \mu \mathrm{Ci})$, continuous $(0.22 \mu \mathrm{Ci} / \mathrm{min})$ infusion of $\left[3-{ }^{3} \mathrm{H}\right]-$ glucose (New England Nuclear, Boston, MA) for isotopic determination of glucose production and glucose utilization. Three hours were allowed for isotopic equilibration, after which baseline blood samples were taken. Substrate oxidation and energy expenditure were measured in all subjects by indirect calorimetry (20). $90 \mathrm{~min}$ before insulin infusion, a transparent plastic ventilated hood was placed over the subject's head and made airtight around the neck. Air flow and $\mathrm{O}_{2}$ and $\mathrm{CO}_{2}$ concentrations in the expired and inspired air were measured by a computerized continuous open-circuit system (Deltatrac; Datex Instruments Co., Helsinki, Finland) (21). Air flow was measured by the air-dilution method, carbon dioxide concentration by a conventional infrared detector, and oxygen concentration by a fast differential paramagnetic oxygen sensor. The monitor has a precision of $2.5 \%$ for oxygen consumption and $1.0 \%$ for carbon dioxide production. Protein oxidation was estimated from urinary excretion of urea before and during insulin hypoglycemia. After the subjects had adapted to the hood and stabilized their breathing pattern, gas-exchange measurements were taken during a 45-min basal period and were continued throughout the studies.

Three sets of experiments were performed at 1-2-wk intervals. In the first set of experiments (study I), to induce moderate hypoglycemia, insulin (Actrapid HM U-40; Novo Research Institute, Copenhagen, Denmark), diluted to $1 \mathrm{U} / \mathrm{ml}$ in $100 \mathrm{ml}$ of $0.9 \% \mathrm{NaCl}$ containing $2 \mathrm{ml}$ of the subject's blood, was intravenously infused at the rate of 0.30 $\mathrm{mU} \cdot \mathrm{kg}^{-1} \cdot \mathrm{min}^{-1}$ from 0 to $180 \mathrm{~min}$ and $0.40 \mathrm{mU} \cdot \mathrm{kg}^{-1} \cdot \mathrm{min}^{-1}$ from 180 to 480 min with a syringe pump (Harvard Apparatus Co., Inc., The Ealing Corp., South Natick, MA). This intravenous rate of insulin infusion was chosen to reproduce the mild hyperinsulinemia observed in previous studies during subcutaneous insulin infusion in normal man (1-6), and to simulate the type of hypoglycemia that may develop in diabetic patients undergoing intensive insulin therapy $(8,9,22-25)$.

In the second set of experiments (study II), insulin was infused as in study I, but propranolol (priming dose $3 \mathrm{mg}$ over $3 \mathrm{~min}$, followed by $0.1 \mathrm{mg} \cdot \mathrm{min}^{-1}$ continuous infusion) and phentolamine (priming dose $10 \mathrm{mg}$ over $3 \mathrm{~min}$, followed by $0.5 \mathrm{mg} \cdot \mathrm{min}^{-1}$ continuous infusion) were infused from 0 to 480 min to block the catecholamine mediated rebound increase in FFA which occurred in study I after $120 \mathrm{~min}$. Because we anticipated from previous studies (6) that combined $\alpha-, \beta$ - adrenergic blockade would result in impaired glucose counterregulation and more severe hypoglycemia, in study II exogenous glucose was infused when needed to maintain plasma glucose concentration at the values observed in study I by means of a modified glucose clamp technique $(3-6,26)$ based on plasma glucose concentration measured every 2.5-5 min. This enabled us to avoid the confounding effects of lower plasma glucose concentrations in study II as compared to study I on glucose fluxes by a mass action effect (27); to prevent greater counterregulatory hormone responses because of severe hypoglycemia (28); and also avoid the discomforts and potential risks of severe hypoglycemia.

In the third set of experiments (study III), insulin, propranolol, and phentolamine were infused as in study II, and when needed, exogenous (cold) glucose was infused to maintain the same plasma glucose concentrations of study II. In addition, in study III heparin $(0.2$ $\mathrm{mU} \cdot \mathrm{kg}^{-1} \cdot \mathrm{min}^{-1}$ from 80 to $480 \mathrm{~min}$ ) and a triglyceride emulsion (10\% Intralipid; Kabi Pharmacia, Stockholm, Sweden, $1 \mathrm{ml} \cdot \mathrm{min}^{-1}$ from 160 to $480 \mathrm{~min}$ ) were infused to reproduce the rebound increase in glycerol and FFA observed in study I after $120 \mathrm{~min}$. In the $10 \%$ Intralipid the total amount of glycerol deriving from triglycerides and phospholipids, with added glycerol was $\approx 330 \mathrm{mM}$. Thus, in study III the estimated rate of glycerol infusion was $\approx 4.8 \mu \mathrm{mol} \cdot \mathrm{kg}^{-1} \cdot \mathrm{min}^{-1}$ under the assumption that the infused triglycerides and phospholipids were fully hydrolized. The above rates of infusion of heparin and $10 \%$ Intralipid in study III were chosen after several pilot experiments based on the "trial and error" method.

Analyses. Blood samples were collected at 30-min intervals and assayed for glucose (Glucose Analyzer; Beckman Instruments, Fullerton, CA), glucose specific activity (29), insulin (30), C-peptide (31), glucagon (32), cortisol (33), growth hormone (34), epinephrine (35), free fatty acids by an enzymatic colororimetric method (NEFA C test kit; Wako Chemicals GmbH, Neuss, Germany), 3- $\beta-\mathrm{OH}$-butyrate (36), glycerol (36), and lactate (36) by previously described methods. In initial pilot experiments with heparin-Intralipid infusion, it was found that in vitro lipolysis (i.e., in tubes where whole blood was collected and allowed to clot for 1-2 $\mathrm{h}$ at room temperature) caused a false increase in plasma FFA up to $\approx 70 \%$. Therefore, to prevent the pitfall of in vitro lipolysis which might have led to an underestimation in the rate of heparin-Intralipid infusion and underreplacement of FFA and glycerol in study III, in all studies blood $(2 \mathrm{ml})$ for FFA determination was collected in tubes containing $50 \mu \mathrm{l}$ of the lipoproteinlipase inhibitor diethyl-p-nitrophenyl-phosphate (Paraoxon; Sigma Chemical Co., St. Louis, MO) diluted to $0.04 \%$ in diethyl ether, as previously described (37). Urine was collected from the onset to the end of each study period to determine nitrogen excretion using the Kjeldahl method (38). Oxidation rates for carbohydrate, fat, and protein were calculated from the measured $\mathrm{O}_{2}$ consumption, $\mathrm{CO}_{2}$ production, and urinary nitrogen excretion (39). Rates of glucose production and uptake in the steady state were computed using the isotope dilution equation. Glucose specific activity reached an apparent steady state in each subject before insulin infusion. After insulin infusion, the rates of glucose appearance (production) and disappearance (utilization) were calculated using the non-steady state equations of De Bodo et al. (40), and were "smoothed" according to the method of Miles et al. (41). Data in text and figures are given as mean $\pm \mathrm{SE}$, and the statistical significance was evaluated using analysis of variance corrected for repeated measures (42).

\section{Results}

Plasma insulin and C-peptide (Fig. 1). In the control experiments (study I), plasma insulin concentration increased from a baseline of $56 \pm 6.6 \mathrm{pmol} / \mathrm{liter}$ to $153 \pm 12 \mathrm{pmol} / \mathrm{liter}$ by $180 \mathrm{~min}$ (insulin infusion rate $0.3 \mathrm{mU} \cdot \mathrm{kg}^{-1} \cdot \mathrm{min}^{-1}$ ) and to $180 \pm 14$ $\mathrm{pmol} /$ liter between 180 and $480 \mathrm{~min}$ (insulin infusion rate 0.4 


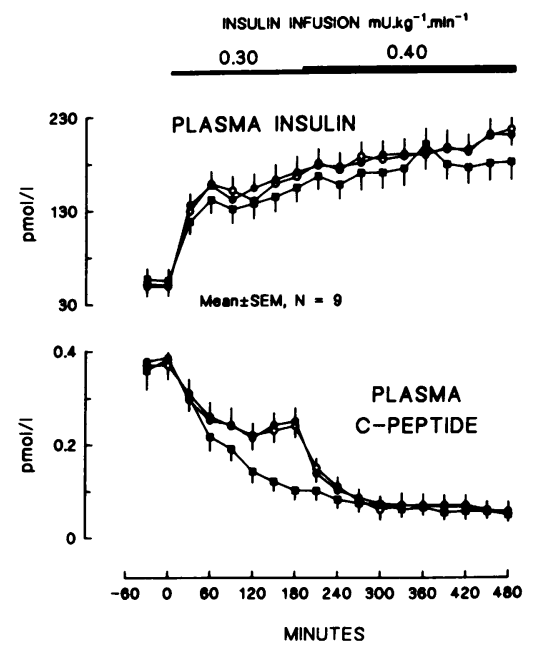

Figure 1. Plasma insulin and C-peptide concentration in studies I-III. n, Saline; $\bullet, \alpha, \beta$-blockade + glucose; o, $\alpha, \beta$ blockade + glucose + heparin + intralipid.

$\mathrm{mU} \cdot \mathrm{kg}^{-1} \cdot \min ^{-1}$ ). In the $\alpha$-, $\beta$-blockade (study II) and heparinIntralipid experiments (study III), the plasma insulin concentrations were superimposable to those of the control experiments.

Plasma C-peptide concentration progressively decreased in all three studies, and was suppressed by $>85 \%$ after $300 \mathrm{~min}$ as compared to the baseline values. However, in studies II and III, plasma C-peptide concentration was less suppressed, from 90 to $210 \mathrm{~min}$ as compared with study $\mathrm{I}(P<0.05)$, a consequence of deinhibition by $\alpha-, \beta$-blockade of suppressed pancreatic $\beta$ cell secretion by catecholamines during hypoglycemia, as previously reported (6). Such an increase in plasma C-peptide was not paralleled by an increased peripheral plasma insulin concentration, probably because the increase in C-peptide was transient $(\approx 90 \mathrm{~min})$ and quantitatively modest $(\approx 0.1 \mathrm{pmol} /$ liter).

Plasma glucose concentrations, rates of exogenous glucose infusion, and rates of glucose production and utilization (Fig. 2). In the control experiments (study I), plasma glucose concentration progressively decreased from a baseline value of $4.8 \pm 0.08 \mathrm{mmol} /$ liter to $2.9 \pm 0.12 \mathrm{mmol} / \mathrm{liter}$ at $480 \mathrm{~min}$. In the $\alpha$-, $\beta$-blockade (study II) and heparin-Intralipid experiments (study III), plasma glucose concentrations were maintained superimposable to those of control experiments $(P=\mathrm{NS})$ by means of infusing exogenous glucose at variable rate between 30 and $480 \mathrm{~min}$. However, in the experiments with heparin-Intralipid in study III, the mean rate of exogenous glucose infusion needed to maintain plasma glucose concentration superimposable to that of the control experiments in study I, was only $\approx 40 \%$ compared to the $\alpha$-, $\beta$-blockade experiments of study II $\left(4.82 \pm 0.44\right.$ vs. $12.0 \pm 1.3 \mu \mathrm{mol} \cdot \mathrm{kg}^{-1} \cdot \mathrm{min}^{-1}$, respectively, $240-480 \mathrm{~min}, P<0.05$ ).

In the control experiments, after an initial suppression at 60 $\mathrm{min}$, the rate of hepatic glucose production increased from a baseline of $11.6 \pm 0.7 \mu \mathrm{mol} \cdot \mathrm{kg}^{-1} \cdot \mathrm{min}^{-1}$ to a peak value of $14.2 \pm 0.90 \mu \mathrm{mol} \cdot \mathrm{kg}^{-1} \cdot \mathrm{min}^{-1}$ at $180 \mathrm{~min}(P<0.05)$. Afterwards, glucose production slowly decreased to $10.0 \pm 0.53$ $\mu \mathrm{mol} \cdot \mathrm{kg}^{-1} \cdot \mathrm{min}^{-1}$ at $480 \mathrm{~min}$. In the $\alpha$-, $\beta$-blockade experiments, the increased rate of glucose production was less than in the control experiments, and overall was $\approx 30 \%$ lower than in the control experiments after $30 \mathrm{~min}(7.48 \pm 0.57$ vs. $11.6 \pm 0.35$

$\mu \mathrm{mol} \cdot \mathrm{kg}^{-1} \cdot \mathrm{min}^{-1}$, respectively, $\left.60-480 \mathrm{~min}, P<0.05\right)$. In the heparin-Intralipid experiments, the rate of hepatic glucose production was initially as suppressed as in the $\alpha$-, $\beta$-blockade experiments until $210 \mathrm{~min}$. Then, hepatic glucose production was less suppressed, and was $\approx 43 \%$ greater than in the $\alpha$-, $\beta$ blockade experiments between 240 and $480 \mathrm{~min}(8.35 \pm 0.22$ vs. $5.85 \pm 0.35 \mu \mathrm{mol} \cdot \mathrm{kg}^{-1} \cdot \mathrm{min}^{-1}$, respectively, $P<0.05$ ).

In the control experiments, the rate of peripheral glucose utilization transiently increased from a baseline value of $11.6 \pm 0.71 \mu \mathrm{mol} \cdot \mathrm{kg}^{-1} \cdot \mathrm{min}^{-1}$ to $14.4 \pm 0.8 \mu \mathrm{mol} \cdot \mathrm{kg}^{-1} \cdot \mathrm{min}^{-1}$ at $180 \mathrm{~min}(P<0.05)$. Afterwards, glucose utilization progressively decreased to $10.2 \pm 0.6 \mu \mathrm{mol} \cdot \mathrm{kg}^{-1} \cdot \mathrm{min}^{-1}$ at $480 \mathrm{~min}$. In the $\alpha-, \beta$-blockade experiments, glucose utilization increased more than in the control experiments between 180 and 210 $\min \left(16.2 \pm 1.2\right.$ vs. $13.4 \pm 0.8 \mu \mathrm{mol} \cdot \mathrm{kg}^{-1} \cdot \mathrm{min}^{-1}$, respectively, $P$ $<0.05$ ). However, in the heparin-Intralipid experiments, after $210 \mathrm{~min}$ the rate of glucose utilization was more suppressed than in the $\alpha$-, $\beta$-blockade experiments and overall was $\approx 36 \%$ lower as compared to the $\alpha$-, $\beta$-blockade experiments $\left(12.3 \pm 0.53\right.$ vs. $19.2 \pm 0.36 \mu \mathrm{mol} \cdot \mathrm{kg}^{-1} \cdot \mathrm{min}^{-1}$, respectively, 240-480 $\mathrm{min}, P<0.05)$.

Plasma counterregulatory hormone concentrations (Fig. 3). In the control experiments, plasma counterregulatory hormones increased to an approximate steady state between 240 and $480 \mathrm{~min}$; by $480 \mathrm{~min}$, glucagon from $101 \pm 18$ to $170 \pm 15$ $\mathrm{pg} / \mathrm{ml}$; epinephrine from $54 \pm 9$ to $375 \pm 74 \mathrm{pg} / \mathrm{ml}$; growth hormone from $2.5 \pm 1.2$ to $9.2 \pm 1.7 \mathrm{ng} / \mathrm{ml}$, and cortisol from $11.5 \pm 0.9$ to $15.2 \pm 1 \mu \mathrm{g} / \mathrm{dl}$. In the $\alpha$-, $\beta$-blockade experiments, the values of plasma glucagon and cortisol were no different when compared to those of the control experiments, whereas plasma epinephrine increased approximately twofold by the end of the study $(893 \pm 109$ vs. $375 \pm 74 \mathrm{pg} / \mathrm{ml}$ at $480 \mathrm{~min}$, study II vs. study I, respectively, $P<0.05$ ), also growth hormone increased approximately twofold $(18 \pm 1.9 \mathrm{vs} .9 .2 \pm 1.7 \mathrm{ng} / \mathrm{ml}$ at $480 \mathrm{~min}$, study II vs. study I, $P<0.05$ ). Finally, in the heparinIntralipid experiments, plasma glucagon, epinephrine and cor-

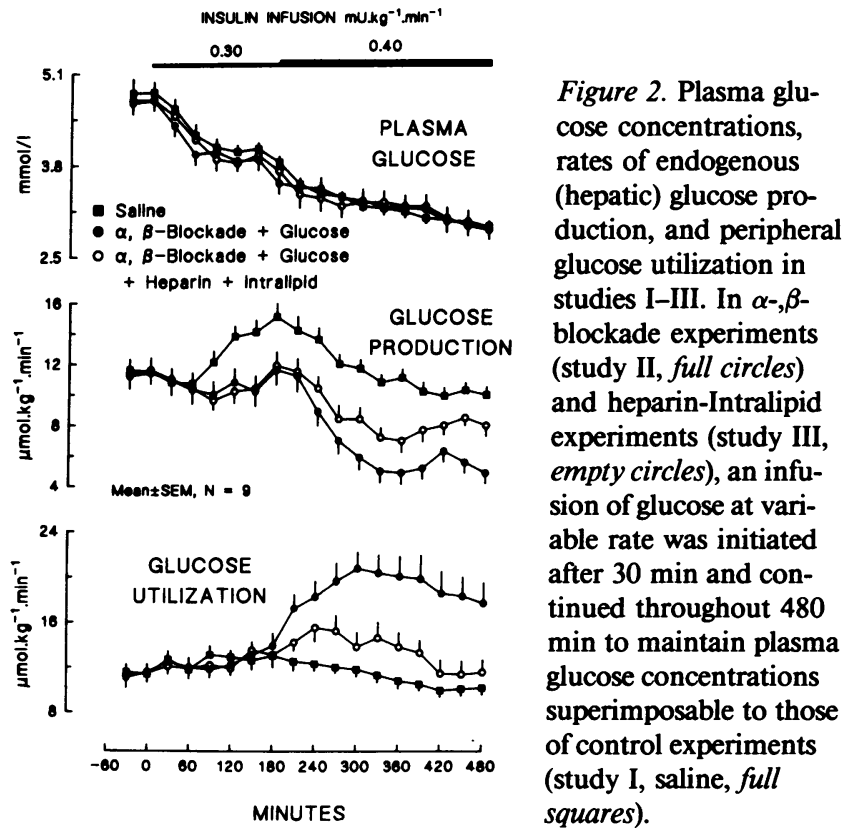




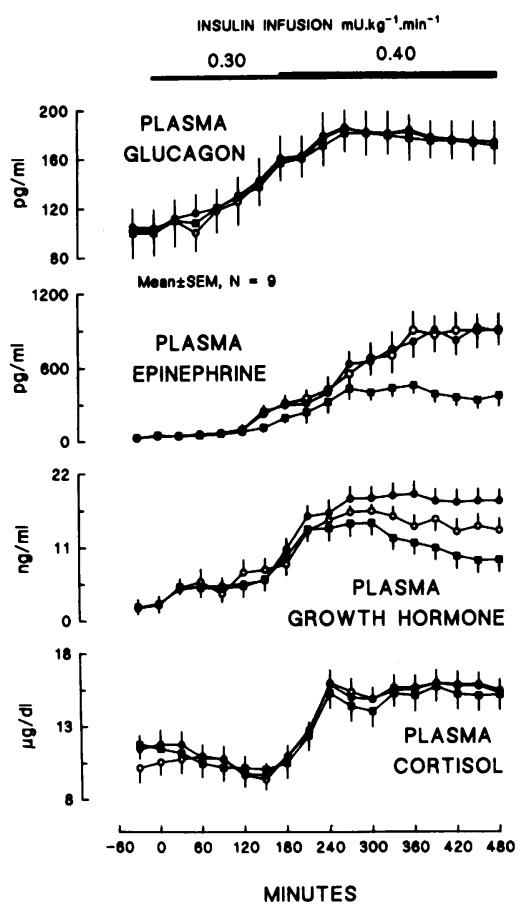

Figure 3. Plasma counterregulatory hormone concentrations in studies I-III. n, Saline; $\bullet$, $\alpha, \beta$-blockade + glucose; o, $\alpha, \beta$-blockade + glucose + heparin + intralipid.

tisol responses were superimposable to those of the $\alpha-, \beta$ blockade experiments, whereas growth hormone responses were $\approx 25 \%$ lower than those of the $\alpha$-, $\beta$-blockade experiments $(13.6 \pm 1.5$ vs. $18 \pm 1.9 \mathrm{pg} / \mathrm{ml}$ at $480 \mathrm{~min}$, respectively, $P<0.05)$.

Plasma glycerol and FFA concentrations, rates of lipid and glucose oxidation (Fig. 4), and $\mathrm{\beta}-\mathrm{OH}$-butyrate and lactate concentrations. In the control experiments, plasma glycerol decreased soon after initiation of insulin infusion from baseline values of $0.042 \pm 0.005 \mathrm{mM}$ to a nadir of $0.025 \pm 0.002 \mathrm{mM}$ at $120 \mathrm{~min}$. Similarly, plasma FFA decreased from $0.43 \pm 0.05$ $\mathrm{mM}$ to a nadir of $0.155 \pm 0.022 \mathrm{mM}$ at $120 \mathrm{~min}$. Afterwards, both plasma glycerol and FFA progressively increased to $0.072 \pm 0.009 \mathrm{mM}$ and $0.782 \pm 0.05 \mathrm{mM}$ by $480 \mathrm{~min}$ (glycerol and FFA, respectively, $P<0.05$ ). In the $\alpha$-, $\beta$-blockade experiments, plasma glycerol and FFA were suppressed more than in the control experiments with nadir values between 180 and 240 min (plasma glycerol $0.025 \pm 0.002 \mathrm{mM}$, plasma FFA $0.058 \pm 0.011 \mathrm{mM})$. Afterwards, both plasma glycerol and FFA increased less than in the control studies (by $480 \mathrm{~min}$ plasma glycerol $0.042 \pm 0.06 \mathrm{mM}$, plasma FFA $0.355 \pm 0.026 \mathrm{mM}, P$ $<0.05)$. In the heparin-Intralipid experiments, plasma glycerol and FFA were initially suppressed, and subsequently rebounded to values superimposable to those of the control studies $(P=\mathrm{NS})$.

Plasma $\beta$-OH-butyrate followed the pattern of plasma glycerol and FFA (data not shown). In the control experiments, plasma $\beta-\mathrm{OH}$-butyrate decreased from a baseline value of $0.171 \pm 0.02 \mathrm{mM}$ to a nadir of $0.072 \pm 0.01 \mathrm{mM}$ at $120 \mathrm{~min}$, then progressively increased to $0.56 \pm 0.07 \mathrm{mM}$ by $480 \mathrm{~min}$. In the $\alpha$-, $\beta$-blockade experiments, plasma $\beta$-OH-butyrate concentration was suppressed more (nadir value at 240 min of $0.48 \pm 0.04$ $\mathrm{mM}$ ), and increased less than in the control experiments (by $480 \mathrm{~min} 0.21 \pm 0.09 \mathrm{mM}$ ). In the heparin-Intralipid experiments, the rebound in plasma $\beta-\mathrm{OH}$-butyrate after $120 \mathrm{~min}$

was superimposable to that of the control studies $(0.59 \pm 0.09$ $\mathrm{mM}$ by $480 \mathrm{~min}, P=$ NS vs. control study).

In the control experiments, plasma lactate (baseline $0.97 \pm 0.06 \mathrm{mM}$ ) did not change (data not shown). In the $\alpha-, \beta$ blockade experiments, plasma lactate progressively decreased after $270 \mathrm{~min}$ and was $0.82 \pm 0.05 \mathrm{mM}$ at $480 \mathrm{~min}, P<0.05$ as compared to the control experiments $(0.95 \pm 0.06 \mathrm{mM})$. In the heparin-Intralipid experiments, plasma lactate concentration was superimposable to that of the $\alpha$-, $\beta$-blockade experiments.

The pattern of lipid oxidation was parallel to plasma glycerol and FFA concentrations. In the control experiments, the rate of lipid oxidation decreased from a baseline value of $2.89 \pm 0.31 \mu \mathrm{mol} \cdot \mathrm{kg}^{-1} \cdot \mathrm{min}^{-1}$ to a nadir of $1.53 \pm 0.21$ $\mu \mathrm{mol} \cdot \mathrm{kg}^{-1} \cdot \mathrm{min}^{-1}$ at $120 \mathrm{~min}$. Afterwards, lipid oxidation progressively increased to $4.10 \pm 0.33 \mu \mathrm{mol} \cdot \mathrm{kg}^{-1} \cdot \mathrm{min}^{-1}$ by 480 min. In the $\alpha$-, $\beta$-blockade experiments, lipid oxidation was suppressed more than in the control study, and increased $\approx 40 \%$ less by $480 \mathrm{~min}\left(2.47 \pm 0.32 \mu \mathrm{mol} \cdot \mathrm{kg}^{-1} \cdot \mathrm{min}^{-1}, P\right.$ $<0.05$ vs. control study). In the heparin-Intralipid experiments, lipid oxidation was superimposable to that of the control studies.

Glucose oxidation increased in the control experiments from a baseline value of $7.56 \pm 1.11 \mu \mathrm{mol} \cdot \mathrm{kg}^{-1} \cdot \mathrm{min}^{-1}$ to a peak of $12.5 \pm 1.12 \mu \mathrm{mol} \cdot \mathrm{kg}^{-1} \cdot \mathrm{min}^{-1}$ at $180 \mathrm{~min}$, and after progressively decreased to $6.85 \pm 0.66 \mu \mathrm{mol} \cdot \mathrm{kg}^{-1} \cdot \mathrm{min}^{-1}$ by $480 \mathrm{~min}$. In the $\alpha$-, $\beta$-blockade experiments, glucose oxidation was not suppressed after $180 \mathrm{~min}$, and remained greater than in the control experiments (by $480 \mathrm{~min} 11.6 \pm 0.94 \mu \mathrm{mol} \cdot \mathrm{kg}^{-1}$. $\mathrm{min}^{-1}$, respectively, $P<0.05$ ). In the heparin-Intralipid experiments, after 180 min the rate of glucose oxidation was suppressed more than in the $\alpha$-, $\beta$-blockade experiments, but less than in the control experiments $(10 \pm 0.52,12.8 \pm 0.25$, and $8.84 \pm 0.64 \mu \mathrm{mol} \cdot \mathrm{kg}^{-1} \cdot \mathrm{min}^{-1}$, respectively, $210-480 \mathrm{~min}, P$ $<0.05)$.

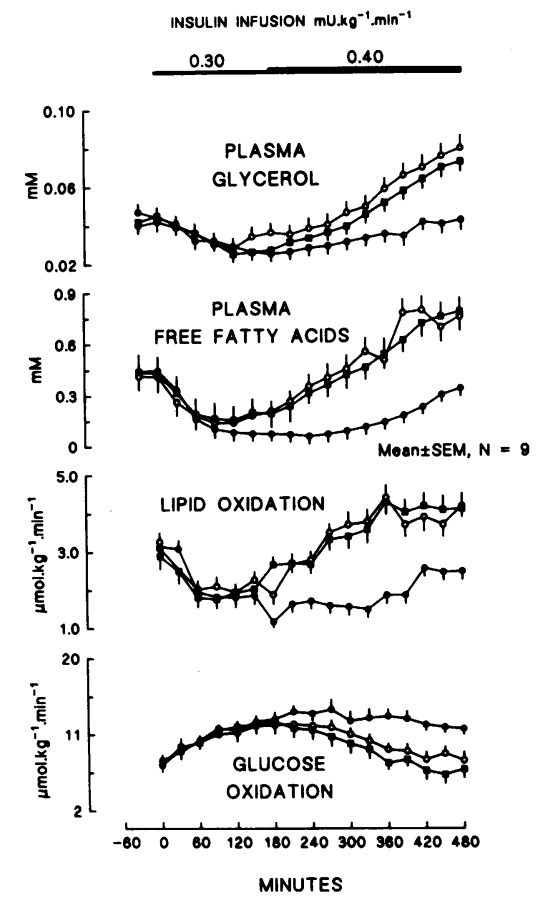

Figure 4. Plasma glycerol and FFA concentrations, and rates of lipid and glucose oxida-

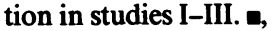
Saline; $\bullet, \alpha, \beta$-blockade + glucose; $\circ, \alpha, \beta$-blockade + glucose + heparin + intralipid. 
Correlations between rates of lipid oxidation and glucose fluxes (Fig. 5). In the heparin-Intralipid experiments, the percent increase in lipid oxidation between 150 and 480 min significantly correlated with the percent decrease in the glucose infusion rate required to reproduce the same plasma glucose concentration of the $\alpha$-, $\beta$-blockade experiments $(r=0.95)$, and with the percent increase in hepatic glucose production $(r$ $=0.88)$, as well as the percent decrease in glucose utilization $(r$ $=0.98)($ all $P<0.05)$. Thus, the greater the availability of the substrates FFA and glycerol, the greater the rate of lipid oxidation, and the greater the increase in hepatic glucose production and the suppression of glucose utilization during the late phase of insulin-induced hypoglycemia.

\section{Discussion}

The present studies reaffirm the recent finding (6) that adrenergic mechanisms do play a key role in the prevention of severe hypoglycemia both at a very early as well as late phase of glucose counterregulation in response to intravenous insulin infusion, and for the first time demonstrate that in a late phase of hypoglycemia the adrenergic contribution to glucose counterregulation is partially dependent on stimulation of lipolysis. Stimulation of lipolysis by adrenergic mechanisms after 180 210 min of counterregulation, contributed in increasing glucose production by $\approx 50 \%$ and suppressing peripheral glucose utilization by $\approx 85 \%$ as compared to experiments in which lipolysis was almost fully blocked. This means that in a late phase of hypoglycemia, the activation of lipolysis by catecholamines is a powerful counterregulatory mechanism. With the exception of the increase in hepatic glucose production in response to severe hypoglycemia per se, i.e., independent of hormonal, neural mechanisms, and nonglucose substrates, the socalled hepatic autoregulation (43), the present study is, to the best of our knowledge, the first demonstration of a direct coun-

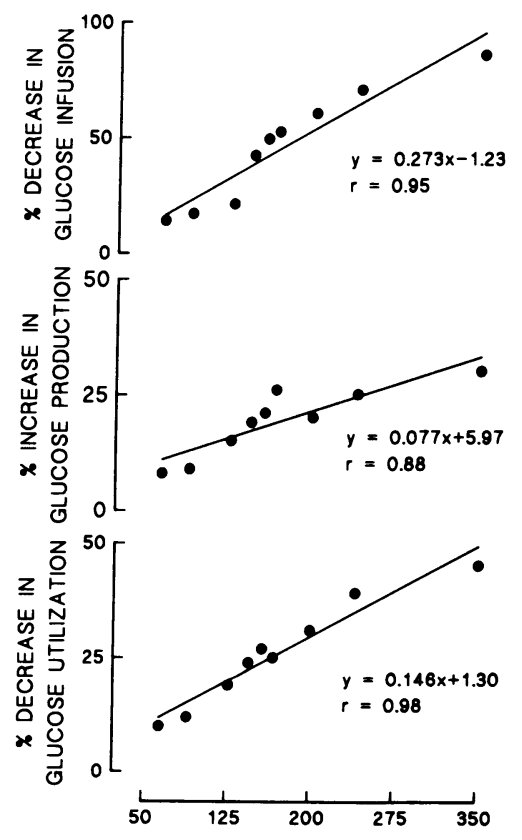

* increase in lipid oxidation
Figure 5. Correlations between the percent increase in lipid oxidation after $150 \mathrm{~min}$ in the heparin-Intralipid experiments (study III) as compared to the $\alpha-, \beta$ blockade experiments (study II) and, top panel, the decrease in the rate of exogenous glucose infusion required to reproduce in study III the same plasma glucose concentration of study II; middle panel, the percent increase in the rate of hepatic glucose production in study III as compared to study II; bottom panel, the percent decrease in the rate of peripheral glucose utilization in study III as compared to study II. terregulatory mechanism mediated by nonglucose substrates (FFA and glycerol) in defense against hypoglycemia in man.

Regarding the contribution of stimulated lipolysis to increased hepatic glucose production in the present experiments, it is likely that both the increased glycerol and FFA fluxes to the liver contributed to sustain primarily gluconeogenesis, and not glycogenolysis, the former being the predominant, if not the exclusive, mechanism of increased glucose production by the liver after $\approx 3 \mathrm{~h}$ of hypoglycemia (13). Normally, glycerol accounts for $\approx 3 \%$ of glucose released from the liver in the postabsorptive state (44), whereas gluconeogenesis is estimated to contribute by one-third to overall glucose production. In addition, gluconeogenesis accounts for $\approx 90 \%$ of overall hepatic glucose output in a model of prolonged hypoglycemia (13) identical to that of the present studies. Thus, it is likely that glycerol-derived gluconeogenesis contributed to at least $10 \%$ of overall hepatic glucose output in the late phase of the present experiments, and possibly even more, because plasma glycerol concentration increased above baseline values after $330 \mathrm{~min}$, and it is well known that the supply of glycerol originating from lipolysis is the major factor regulating glycerol conversion to glucose $(45,46)$. In this regard, the estimate of the rate of glycerol infusion in the experiments of study III in which heparin and $10 \%$ Intralipid were infused, yielded a figure of $\approx 4.8$ $\mu \mathrm{mol} \cdot \mathrm{kg}^{-1} \cdot \mathrm{min}^{-1}$ assuming a complete hydrolysis of the infused fat emulsion into FFA and glycerol in plasma. This rate is almost three times greater than the basal turnover rate of glycerol in $\operatorname{man}\left(\approx 1.7 \mu \mathrm{mol} \cdot \mathrm{kg}^{-1} \cdot \mathrm{min}^{-1}\right)(44)$. However, because in the late phase of hypoglycemia, plasma glycerol concentration increases by approximately three times as compared to its early nadir (Fig. 4, study I), it is likely that rates of glycerol appearance, two to three times greater than the baseline are required to produce such a sustained increase in plasma glycerol concentration by the end of studies. In fact, using such rates of glycerol infusion, in the experiments of study III, the plasma glycerol concentrations very closely matched those of the control experiments of study I. Taken together, these considerations support the concept that the increase in hepatic glucose production observed in the present heparin-Intralipid experiments of study III as compared to that of the $\alpha-, \beta$ blockade of study II was due to physiological, and not pharmacological glycerol replacement, closely mimicking the catecholamine stimulated lipolysis of control study $I$.

It is likely that not only glycerol, but also FFA contributed to the increase in the rate of hepatic glucose production observed in the heparin-Intralipid as compared to the $\alpha-, \beta$ blockade experiments of the present studies. Indirect support for an interaction between FFA and hepatic glucose production has been derived from studies demonstrating a positive correlation between FFA or lipid oxidation and rates of hepatic glucose production (47-49). In fact, FFA generated acetyl-CoA within the liver, stimulates pyruvate carboxylase, the first committed step of the gluconeogenic pathway (50). By this mechanism, FFA can increase gluconeogenesis $(47,51-53)$ and hepatic glucose production (54-57). In the present studies, because of prolonged hypoglycemia the liver was exposed to the gluconeogenetic effects of glucagon (58), cortisol (58), and most likely also growth hormone (59). It is possible that under these conditions even the apparently modest increase in plasma FFA $(\approx 0.5 \mathrm{mM})$ in the present experiments accelerated gluconeogenesis and increased hepatic glucose produc- 
tion. This concept is supported in the present studies by the correlation found between the increase in lipid oxidation (primarily FFA) and hepatic glucose production after activation of lipolysis by counterregulation in the heparin-Intralipid experiments as compared to the $\alpha$-, $\beta$-blockade experiments (Fig. 5 , middle panel).

Although the design of the present experiments does not allow one to distinguish between the relative contribution of glycerol and FFA to the increased hepatic glucose production in the late phase of hypoglycemia, it should be considered that the release of both these substrates from adipose tissue is driven by adrenergic mechanisms. Adrenergic mechanisms may sustain gluconeogenesis via two mechanisms, i.e., by providing greater flux of gluconeogenetic substrates (such as lactate, glycerol, alanine, etc.) and FFA from peripheral tissues, and by increasing the efficiency of the intrahepatic conversion of these substrates to glucose (60). It is possible that the increase in hepatic glucose production observed in the present heparin-Intralipid experiments of study III, reflect increased gluconeogenesis secondary to greater supply of substrates and FFA to the liver. However, because the effects of catecholamines were blocked, it is also possible that the overall efficiency of gluconeogenesis was reduced. Thus, despite a normal supply of glycerol and FFA to the liver, hepatic glucose production was not normalized in the heparin-Intralipid experiments of study III.

Regarding the suppression of glucose utilization by catecholamine-stimulated lipolysis, the present studies provide a direct evidence that this effect is secondary to a substrate competition effect between FFA and glucose, both in the oxidation and in the utilization processes of peripheral tissues. This finding is also consistent with Randle's glucose-fatty acid hypothesis $(61,62)$. Because the competition between FFA and glucose utilization becomes evident only when glucose uptake by peripheral tissues is increased by hyperinsulinemia $(14,15)$, and because the muscle is the primary site of increased glucose utilization promoted by insulin (63), it is assumed that the in vivo effects of elevated FFA in suppressing glucose oxidation and utilization take place at the muscle level.

In the present studies, the rates of glucose oxidation decreased, whereas those of lipid oxidation increased after stimulation of lipolysis after $240 \mathrm{~min}$ (Fig. 4), as previously reported $(18,64)$. In addition, the increase in the rates of lipid oxidation was inversely correlated with the decrease in the rates of glucose utilization in the heparin-Intralipid as compared to the $\alpha$-, $\beta$-blockade experiments (Fig. 5, lower panel). However, these data must be interpreted with some caution. During prolonged hypoglycemia (13), increased gluconeogenesis from amino acids increases nitrogen production, whereas increased production of ketone bodies may influence gas exchange (39). This introduces a theoretical limitation in the calculation of accurate partitioning of whole body oxidative metabolism into its components of net carbohydrate, fat, and protein oxidation (39). This would cause an underestimation of glucose oxidation directly proportional to the amount of de novo synthetized glucose from alanine, as well as an underestimation of lipid oxidation (39). Therefore, the decrease in carbohydrate oxidation rates observed in the present experiments after 240 min are, if anything, an overestimation of the suppression of the rates of glucose oxidation by increased lipid oxidation. In this regard, the rate of glucose oxidation would be underestimated less in the $\alpha-, \beta$-blockade experiments, because the adrenergic blockade would suppress the catecholamine-induced gluconeogenesis (60). On the other hand, in the heparinIntralipid experiments, FFA-driven gluconeogenesis would again result in a greater underestimation of glucose oxidation as compared to the $\alpha$-, $\beta$-blockade experiments, although quantitatively lower than in the control experiments where rates of hepatic glucose production (and most likely gluconeogenesis) are greater. Although these methodological limitations make it difficult to estimate quantitatively the rates of glucose oxidation, it is likely that the suppression of glucose oxidation observed in the present studies in a late phase of hypoglycemia is not the consequence of a direct adrenergic response. In fact, Wolfe and Shaw (65) demonstrated in the dog that epinephrine does not suppress glucose oxidation if glucose flux, FFA availability, and glucoregulatory hormones are kept constant. Taken together, the qualitative changes of glucose oxidation observed in the present studies and, more importantly, the changes in the rates of glucose utilization are nevertheless consistent with the substrate competition hypothesis between glucose and FFA. The results of the present studies suggest that the glucose-FFA cycle $(61,62)$ is a physiological mechanism which induces peripheral (muscular) insulin resistance in a late phase of hypoglycemic glucose counterregulation. Thus, the glucoseFFA cycle is operative not only in obesity (66) and type 2 diabetes mellitus $(67,68)$, but also intervenes as a physiological mechanism in defense against hypoglycemia.

It is interesting to note that in previous studies $(14,15)$, evidence of a glucose-FFA substrate competition effect in vivo in peripheral tissues (primarily muscle) has been demonstrated for supraphysiological increases in plasma FFA in the order of 1.5-2.5 mM above those of control studies. In contrast, in the present studies, the substrate competition effect between FFA and glucose for peripheral glucose utilization is clearly evident with only a difference of $\approx 0.5 \mathrm{mM}$ in plasma FFA concentration. This indicates that under conditions of hypoglycemic glucose counterregulation, peripheral tissues (primarily muscle) are exquisitely sensitive to minor changes in plasma FFA availability, and that plasma FFA concentration might be a much more important regulatory mechanism in the physiology of muscle oxidation and utilization of glucose than currently appreciated.

In theory, the rebound increase in $\beta$-OH-butyrate which was parallel to FFA in the present studies, might have competed for glucose utilization in the brain, thus contributing to suppress the rate of glucose utilization (16). However, it is unlikely that this was the case because the counterregulatory hormonal responses observed during suppression $(\alpha$-, $\beta$-blockade experiments) and replacement (heparin-Intralipid experiments) of plasma $\beta$-OH-butyrate concentration were almost identical. As recently reported (17), if plasma $\beta$-OH-butyrate was utilized as a fuel instead of glucose, a lower counterregulatory hormone response would have been observed in the latter as compared to the former experiments because of compensation of neuroglycopenia by oxidation of ketone bodies.

In their recent study, Caprio et al. (18) did not find a counterregulatory role of catecholamine-stimulated increase in FFA in a model of hypoglycemia similar to that of the present experiments. Probably the shorter duration of their study $(\approx 240$ vs. $\approx 480$ min of the present studies) and the lower peripheral plasma insulin concentration achieved $(\approx 140$ vs. $\approx 180$ pmol/liter of the present experiments) accounted for the lack of 
$\beta$-adrenergic effects on the extrahepatic mechanisms of glucose utilization (18). However, in their study it is unclear as to why $\beta$-blockade did not result in impaired hepatic glucose counterregulation, since catecholamines do play a key role in increasing hepatic glucose production in defense against hypoglycemia at a very early phase (6). The only difference between the Caprio et al. study (18) and the studies in which catecholamines have been found to be important (6, present study) is that in the Caprio et al. study (18) only $\beta$-blockade was carried out, whereas in previous studies (6) and in the present studies, combined $\alpha$-, $\beta$-blockade was performed. Isolated $\beta$-blockade during hypoglycemia may indirectly enhance $\alpha$-adrenergic mediated effects $(69,70)$, such as suppression of endogenous insulin secretion more rapidly than in the control study (6). Thus, it is possible that in the study by Caprio et al. (18) a lower portal hyperinsulinemia during isolated $\beta$-blockade as compared to the control study masqueraded the contribution of catecholamines on hepatic glucose counterregulation.

In interpreting the results of the present studies, the difference in plasma growth hormone concentration between the $\alpha$-, $\beta$-blockade and the heparin-Intralipid experiments should be taken into account. First, plasma growth hormone concentration was greater in the $\alpha$-, $\beta$-blockade and heparin-Intralipid experiments as compared to control experiments because of deinhibition of the $\beta$-adrenergic tone by propranolol (71) as previously reported $(6,29,72)$. Second, in the late phase of heparin-Intralipid experiments, growth hormone was lower than in the $\alpha$-, $\beta$-blockade experiments, most likely because elevated plasma FFA suppress growth hormone secretion $(73,74)$. However, if anything, this would underestimate the contribution of stimulated lipolysis to counterregulation, because the subjects should be more insulin sensitive in the heparin-Intralipid than in the $\alpha$-, $\beta$-blockade experiments because of the less increased plasma $\mathrm{GH}$ responses.

The results of the present studies expand our understanding of the counterregulatory mechanisms of catecholamines in defense against hypoglycemia in man. In an early phase, catecholamines suppress endogenous insulin secretion (Fig. 1), and contribute to increase hepatic glucose production after $30 \mathrm{~min}$ (Fig. 2), most likely by stimulating glycogenolysis. Later, they continue to increase hepatic glucose production (here gluconeogenesis is probably the major source), but also suppress peripheral glucose utilization. Clutter et al. (75) have named the catecholamine-induced suppression of endogenous insulin secretion as an indirect effect, and the increased hepatic glucose production and the suppressed glucose utilization as direct counterregulatory effects of catecholamines. The present studies reaffirm that catecholamines suppress endogenous insulin secretion in an early phase of hypoglycemia (Fig. 1), as recently reported (6). In addition, the present studies for the first time indicate that the indirect counterregulatory effects of catecholamines include stimulation of lipolysis. This mechanism plays an important counterregulatory role because it sustains hepatic glucose production and suppresses peripheral glucose utilization, ultimately preventing more severe hypoglycemia.

The present studies also allow one to speculate on the quantitative role of the indirect counterregulatory effects of adrenergic mechanisms mediated by accelerated lipolysis, as compared to its direct effects (Table I). In the late phase of hypoglycemia (240-480 $\mathrm{min}$ ), the total contribution of catecholamines (direct + indirect effects) to hepatic glucose production increased
Table I. Contribution of the Effects of Catecholamines to Increased Glucose Production and Suppressed Glucose Utilization in the Late Phase (240-480 min) of Insulin Hypoglycemia

\begin{tabular}{lccc}
\hline & Study I & Study II & Study III \\
\hline $\begin{array}{l}\text { Hepatic glucose production } \\
\left(\mu \mathrm{mol} \cdot \mathrm{kg}^{-1} \cdot \mathrm{min}^{-1}\right)\end{array}$ & $10.9 \pm 0.29$ & $5.85 \pm 0.35$ & $8.35 \pm 0.22$ \\
Percentage of control study & $100 \%$ & $\approx 54 \%$ & $\approx 77 \%$ \\
$\begin{array}{c}\text { Glucose utilization } \\
\left(\mu \mathrm{mol} \cdot \mathrm{kg}^{-1} \cdot \mathrm{min}^{-1}\right)\end{array}$ & $11.1 \pm 0.29$ & $19.2 \pm 0.36$ & $12.3 \pm 0.53$ \\
Percentage of control study & $58 \%$ & $100 \%$ & $64 \%$ \\
\hline
\end{tabular}

The overall (direct + indirect) effects are estimated as difference between the $\alpha$-, $\beta$-blockade studies (study II) and the control studies (study I). The indirect effects are estimated as difference between $\alpha$-, $\beta$-blockade + heparin + Intralipid studies (study III) and $\alpha-, \beta$ blockade studies (study II).

by overall counterregulation, calculated as the difference between study I and study II, was $\approx 5 \mu \mathrm{mol} \cdot \mathrm{kg}^{-1} \cdot \mathrm{min}^{-1}$, i.e., $\approx 46 \%$ of the hepatic glucose production of study I (saline). The indirect effects of adrenergic-mediated lipolysis accounted for $\approx 2.5 \mu \mathrm{mol} \cdot \mathrm{kg}^{-1} \cdot \mathrm{min}^{-1}$, i.e., $\approx 50 \%$ of the total adrenergic contribution to hepatic glucose production. Regarding glucose utilization, overall catecholamines suppressed glucose utilization by $\approx 8 \mu \mathrm{mol} \cdot \mathrm{kg}^{-1} \cdot \mathrm{min}^{-1}$ (difference between study II and study I), i.e., they reduced glucose utilization by $\approx 42 \%$ (direct + indirect effects). Catecholamine-mediated lipolysis (difference between studies II and III) accounted for by $\approx 7$ $\mu \mathrm{mol} \cdot \mathrm{kg}^{-1} \cdot \mathrm{min}^{-1}$, i.e., $\approx 85 \%$ of the catecholamine effects on glucose utilization are indirect. Thus, the contribution of stimulated lipolysis to hypoglycemic glucose counterregulation is relevant both to the liver as well as to the muscle, but it appears to be quantitatively more important for the latter rather than for the former.

It should be pointed out that these indirect counterregulatory effects of adrenergic mechanisms mediated by accelerated lipolysis became important only in a late phase of hypoglycemia, i.e., after three hours. Thus, these indirect mechanisms may contribute in preventing a more severe hypoglycemia during prolonged, not short-term hypoglycemia (1). In this regard, it is interesting to note that other counterregulatory hormones such as glucagon, cortisol, and growth hormone failed to fully compensate for the direct effects of catecholamine at the end of study III of the present experiments where plasma glycerol and FFA were increased by the heparin-Intralipid infusion. This observation is consistent with our previous finding of lack of reciprocal compensation between counterregulatory hormones, when one of them fails to increase (3-6). It is also tempting to speculate on the possibility that activation of adrenergic mechanisms under conditions different from hypoglycemia for example, stress might cause hyperglycemia at least in part by the indirect mechanism of stimulated lipolysis demonstrated in the present experiments.

The stimulated lipolysis observed in the present experiments after approximately three hours of activated counterregulation, was largely the result of increased secretion of catecholamines. However, the late increase in plasma glycerol and FFA concentrations after five to six hours despite adrenergic $\alpha$-, $\beta$-blockade in study II, indicates that most likely other coun- 
terregulatory hormones such as growth hormone (3) and cortisol (4) contributed to the late FFA and glycerol rebound. Therefore, it is possible that not only catecholamines, but also growth hormone and cortisol, which possess lipolytic actions in hypoglycemic counterregulation $(3,4)$, increase hepatic glucose production and suppress peripheral glucose utilization at least in part by indirect mechanisms, i.e., stimulated lipolysis.

In summary, the present studies indicate that adrenergic mechanisms counterregulate hypoglycemia partially by indirect mechanisms, i.e., by stimulating lipolysis and increasing the glycerol and FFA fluxes to the liver and muscle. This increases hepatic glucose production, suppresses peripheral glucose utilization, and ultimately prevents more severe hypoglycemia. Further studies are needed to establish whether such a stimulated lipolysis during hypoglycemia contributes to glucose counterregulation not only under the conditions of $\alpha-, \beta$ blockade, as in the present study, but also when the hepatic and extrahepatic effects of catecholamines (and other counterregulatory hormone) are not inhibited.

\section{Acknowledgments}

The authors gratefully acknowledge Dr. Paul Hjemdhal for his generous help and cooperation setting up the HPLC method for the plasma catecholamine assay in the Laboratories of the Istituto di Medicina Interna e Scienze Endocrine e Metaboliche, Università di Perugia; Dr. John Miles for his key suggestions regarding the correct handling of serum for FFA determination; Professor Eleuterio Ferrannini for his thorough criticism; Ms. Patricia Boyce for her careful editorial assistance.

This work was supported by the Consiglio Nazionale delle Ricerche (CNR grant 90.02412.CT04; and finalized "Project Aging" grant 91.00325.PF40).

\section{References}

1. De Feo, P., G. Perriello, S. De Cosmo, M. M. Ventura, P. J. Campbell, P. Brunetti, J. E. Gerich, and G. B. Bolli. 1986. Comparison of glucose counterregulation during short-term and prolonged hypoglycemia in normal humans. Diabetes. 35:563-569.

2. De Feo, P., G. Perriello, M. M. Ventura, P. Brunetti, F. Santeusanio, J. E. Gerich, and G. B. Bolli. 1987. The pancreatic-adrenocortical-pituitary clamp technique for study of counterregulation in humans. Am. J. Physiol. 252:E565E570.

3. De Feo, P., G. Perriello, E. Torlone, M. M. Ventura, F. Santeusanio, P. Brunetti, J. E. Gerich, and G. B. Bolli. 1989. Demonstration of role for growth hormone in glucose counterregulation. Am. J. Physiol. 256:E835-E843.

4. De Feo, P., G. Perriello, E. Torlone, M. M. Ventura, C. Fanelli, F. Santeusanio, P. Brunetti, J. E. Gerich, and G. B. Bolli. 1989. Contribution of cortisol to glucose counterregulation in man. Am. J. Physiol. 257:E35-E42.

5. De Feo, P., G. Perriello, E. Torlone, C. Fanelli, M. M. Ventura, F. Santeusanio, P. Brunetti, J. E. Gerich, and G. B. Bolli. 1991. Evidence against important catecholamine compensation for absent glucagon counterregulation. Am. J. Physiol. 260:E203-E212.

6. De Feo, P., G. Perriello, E. Torlone, C. Fanelli, M. M. Ventura, F. Santeusanio, P. Brunetti, J. E. Gerich, and G. B. Bolli. 1991. The contribution of adrenergic mechanisms to glucose counterregulation in humans. Am. J. Physiol. 261:E725-E736.

7. Rizza, R., M. Haymond, C. Verdonk, L. Mandarino, J. Miles, F. Service, and J. Gerich. 1981. Pathogenesis of hypoglycemia in insulinoma patients: suppression of hepatic glucose production by insulin. Diabetes. 30:377-381.

8. Bolli, G. B., G. D. Dimitriadis, G. B. Pehling, B. A. Baker, M. W. Haymond, P. E. Cryer, and J. E. Gerich. 1984. Abnormal glucose counterregulation after subcutaneous insulin in insulin-dependent diabetes mellitus. $N$. Engl. J. Med. 310:1706-1711.

9. Bendtson, I., A. Kverneland, S. Pramming, and C. Binder. 1988. Incidence of nocturnal hypoglycemia in insulin-dependent diabetic patients on intensive therapy. Acta. Med. Scand. 223:543-548. 1245.

10. Gerich, J. E. 1989. Oral hypoglycemic agents. N. Engl. J. Med. 321:1231-
11. Bolli, G. B. 1990. From physiology of glucose counterregulation to prevention of hypoglycemia in Type I diabetes mellitus. Diabetes Nutr. Metab. 3:333-349.

12. Boyle, P. J., and P. E. Cryer. 1991. Growth hormone, cortisol, or both are involved in defense against, but are not critical to recovery from prolonged hypoglycemia in humans. Am. J. Physiol. 260:E395-E402.

13. Lecavalier, L., G. B. Bolli, P. Cryer, and J. Gerich. 1989. Contribution of gluconeogenesis and glycogenolysis during glucose counterregulation in normal man. Am. J. Physiol. 256:E844-851.

14. Ferrannini, E., E. J. Barrett, S. Bevilacqua, and R. A. De Fronzo. 1983. Effects of fatty acids on glucose production and utilization in man. J. Clin. Invest. 72:1737-1747.

15. Bonadonna, R., K. Zych, C. Boni, E. Ferrannini, and R. A. De Fronzo. 1989. Time dependence of the interaction between lipid and glucose in humans. Am. J. Physiol. 257:E49-E56.

16. Pardridge, W. M. 1983. Brain metabolism: a perspective from the bloodbrain barrier. Physiol. Rev. 63:1481-1535.

17. Amiel, S. A., H. R. Archibald, G. Chusney, A. J. K. Williams, and E. A. M. Gale. 1991. Ketone body infusion lowers hormonal responses to hypoglycaemia: evidence for acute cerebral utilization of a non-glucose fuel. Clin. Sci. (Lond.). 81:189-194.

18. Caprio, S., R. A. Gelfand, W. V. Tamborlane, and R. S. Sherwin. 1989. Oxidative fuel metabolism during mild hypoglycemia: critical role of free fatty acids. Am. J. Physiol. 256:E413-E419.

19. McGuire, E., J. Helderman, J. Tobin, R. Andres, and M. Berman. 1976. Effects of arterial versus venous sampling on analysis of glucose kinetics in man. J. Appl. Physiol. 41:565-573.

20. Jequier, E. 1985. Direct and indirect calorimetry in man. In Substrate and Energy Metabolism. J. S. Garrow and D. Halliday, editors. John Wiley \& Sons Ltd., London. 82-92.

21. Merilainen, P. T. 1987. Metabolic monitor. Int. J. Clin. Monit. Comput. 4:167-177.

22. Bending, J. J., J. C. Pickup, A. C. G. Collins, and H. Keen. 1985. Rarity of a marked "dawn phenomenon" in diabetic subjects treated by continuous subcutaneous insulin infusion. Diabetes Care. 8:28-33.

23. Arias, P., W. Kerner, H. Lier, I. Navascues, and E. F. Pfeiffer. 1985 Incidence of hypoglycemic episodes in diabetic patients under continuous subcutaneous insulin infusion and intensified conventional insulin treatment: assessment by means of semi-ambulatory 24-hour continuous blood glucose monitoring. Diabetes Care. 8:134-40.

24. Perriello, G., P. De Feo, E. Torlone, F. Calcinaro, M. M. Ventura, G. Basta, F. Santeusanio, P. Brunetti, J. E. Gerich, and G. B. Bolli. 1988. Asymptomatic nocturnal hypoglycemia: a cause for deterioration of glycemic control in diabetes mellitus. 1988. N. Engl. J. Med. 319:1233-1239.

25. Lager, I., P. Lonnroth, H. von Schenk, and U. Smith. 1983. Reversal of insulin resistance in type I diabetes with continuous subcutaneous insulin infusion. Br. Med. J. 287:1661-1664.

26. De Feo, P., V. Gallai, G. Mazzotta, G. Crispino, E. Torlone, G. Perriello, M. M. Ventura, F. Santeusanio, P. Brunetti, and G. B. Bolli. 1988. Modest decrements in plasma glucose concentration cause early impairment in cognitive function and later activation of glucose counterregulation in the absence of hypoglycemic symptoms in normal man. J. Clin. Invest. 82:436-444.

27. Gottesman, I., L. Mandarino, and J. Gerich. 1984. Use of glucose uptake and glucose clearance for the evaluation of insulin action in vivo. Diabetes. 33:184-191.

28. De Feo, P., G. Perriello, S. De Cosmo, M. M. Ventura, E. Torlone, C. Fanelli, F. Santeusanio, G. B. Bolli, and P. Brunetti. 1989. Adrenergic mechanisms do not contribute to glucose counterregulation during acute insulin-induced hypoglycemia in normal man. Diabetes Nutr. Metab. 2:111-118.

29. Rizza, R. A., P. E. Cryer, and J. E. Gerich. 1979. Role of glucagon, catecholamines, and growth hormone in human glucose counterregulation: effects of somatostatin and combined $\alpha$ - and $\beta$-adrenergic blockade on plasma glucose recovery and glucose flux rates after insulin-induced hypoglycemia. $J$. Clin. Invest. 64:62-71.

30. Herbert, V., K. S. Lav, G. Gottlieb, and S. J. Bleicher. 1965. Coated charcoal immunoassay of insulin. J. Endocrinol. Metab. 25:1375-1379.

31. Faber, O. C. Binder, J. Markussen, L. Heding, V. Naithand, H. Kuzuya, P. Blix, D. Horwitz, and A. Rubenstein. 1978. Characterization of seven C-peptide antisera. Diabetes 27 (Suppl. 1):170-177.

32. Faloona, G., and R. H. Unger. 1974. Glucagon. In Methods of Hormone Radioimmunoassay. B. Jaffe and H. Behrman, editors. Academic Press, New York. 317-330.

33. Seth, J., and L. M. Brown. 1978. A simple RIA for plasma cortisol. Clin. Chim. Acta. 86:109-120.

34. Peake, G. 1974. Growth hormone. In Methods of Hormone Radioimmunoassay. B. Jaffe and H. Berhman, editors. Academic Press, New York. 103-121.

35. Hjemdahl, P., M. Daleskog, and T. Kahan. 1979. Determination of plasma catecholamines by high performance liquid chromatography with electro- 
chemical detection: comparison with a radioenzymatic method. Life Sci. 25:131138.

36. Lowry, O., and J. Passonneau. 1972. Typical fluorimetric procedures for metabolite assays. In A Flexible System for Enzymatic Analysis. O. Lowry and J. Passonneau, editors. Academic Press, New York. 89-92.

37. Miles, J., R. O. Glassock, J. Aikens, J. Gerich, and M. Haymond. 1983. A microfluorimetric method for the determination of free fatty acids on plasma. $J$. Lipid Res. 24:96-99.

38. Hawk, P. B. 1947. Kjeldhal method. In Practical Physiological Chemistry 12th ed. Blakiston, Toronto. 814-822.

39. Ferrannini, E. 1988. The theoretical basis of indirect calorimetry: a review. Metab. Clin. Exp. 37:287-301.

40. De Bodo, R., R. Steele, N. Altzuler, A. Dunn, and J. Bishop. 1963. On the hormonal regulation of carbohydrate metabolism: studies with ${ }^{14} \mathrm{C}$ glucose. $R e$ cent Prog. Horm. Res. 19:445-448.

41. Miles, J., M. Haymond, and J. Gerich. 1982. Effects of free fatty acids, insulin, glucagon, and adrenaline on ketone body production in humans. In Metabolic Acidosis. Ciba Foundation 87. Pitman Books Ltd., London. 192-213.

42. Zar, J. 1984. Biostatistical Analysis. Prentice Hall, Englewood Cliffs, NJ. $168-260$.

43. Bolli, G. B., P. De Feo, G. Perriello, S. De Cosmo, M. M. Ventura, P. Campbell, P. Brunetti, and J. E. Gerich. 1985. Role of hepatic autoregulation in defense against hypoglycemia in humans. J. Clin. Invest. 75:1623-1631.

44. Nurjhan, N., P. J. Campbell, F. P. Kennedy, J. M. Miles, and J. E. Gerich. 1986. Insulin dose-response characteristics for suppression of glycerol release and conversion to glucose in humans. Diabetes. 35:1326-1331.

45. Shaw, W., T. Issekutz, and B. Issekutz. 1976. Gluconeogenesis from glycerol at rest and during exercise in normal, diabetic and methylprednisolonetreated dogs. Metab. Clin. Exp. 25:329-339.

46. Keller, U., J. Chiasson, J. Liljenquist, A. Cherrington, A. Jennings, and O. Crofford. 1977. The roles of insulin, glucagon and free fatty acids in the regulation of ketogenesis in dogs. Diabetes. 26:1040-51.

47. Golay, A., A. L. M. Swislocki, Y.-D. I. Chen, and G. M. Reaven. 1987. Relationship between free fatty acid concentration, endogenous glucose production, and fasting hyperglycemia in normal and non-insulin dependent diabetic individuals. Metab. Clin. Exp. 36:692-696.

48. Lillioja, S., C. Bogardus, D. M. Mott, A. L. Kennedy, W. C. Knowler, and B. V. Howard. 1985. Relationship between insulin-mediated glucose disposal and lipid metabolism in man. J. Clin. Invest. 75:1106-1115.

49. Bogardus, C., S. Lillioja, B. V. Howard, G. Reaven, and D. Mott. 1984. Relationship between insulin secretion, insulin action, and fasting plasma glucose concentration in nondiabetic and non-insulin-dependent diabetic subjects. $J$. Clin. Invest. 74:1238-1246.

50. Williamson, J., R. A. Kreisberg, and P. W. Felts. 1966. Mechanisms for the stimulation of gluconeogenesis by fatty acids in perfused rat liver. Proc. Natl. Acad. Sci. USA. 56:247-254.

51. Blumenthal, S. A. 1983. Stimulation of gluconeogenesis by palmitic acid in rat hepatocytes. Evidence that this effect can be dissociated from the provision of reducing equivalents. Metab. Clin. Exp. 32:982-987.

52. Friedman, B., E. Goodman, and S. Weinhouse. 1970. Dietary and hormonal effects on gluconeogenesis and glycogenesis from pyruvate $3-{ }^{14} \mathrm{C}$, fructose $\mathrm{U}-{ }^{14} \mathrm{C}$, and glycerol $2-{ }^{14} \mathrm{C}$ in the rat. Endocrinology. 86:1264-1271.

53. Struck, E., J. Ashmore, and O. Wieland. 1966. Effects of glucagon and long chain fatty acids on glucose production by isolated perfused rat liver. $A d v$. Enzyme Regul. 4:219-224.

54. Ruderman, N. B., C. J. Toews, and E. Shafir. 1969. Role of free fatty acids in glucose homeostasis. Arch. Intern. Med. 123:299-313.

55. Taskinen, M.-R., T. Sane, E. Helve, S.-L. Karonen, E. A. Nikkila, and H. Yki-Jarvinen. 1989. Bedtime insulin for suppression of overnight free-fatty acid, blood glucose, and glucose production in NIDDM. Diabetes. 38:580-588.
56. Yki-Jarvinen, H., E. Helve, T. Sane, N. Nurjhan, and M.-R. Taskinen. 1989. Mechanism for insulin inhibition of overnight glucose production and gluconeogenesis from lactate in NIDDM. Am. J. Physiol. 256:E732-739.

57. Exton, J. H., J. G. Corbin, and C. R. Park. 1969. Control of gluconeogenesis in liver: differential effects of fatty acids and glucagon on ketogenesis and gluconeogenesis in the perfused rat liver. J. Biol. Chem. 244:4095-5102.

58. Lecavalier, L., G. Bolli, and J. Gerich. 1990. Glucagon-cortisol interactions on glucose turnover and lactate gluconeogenesis in normal humans. Am. J. Physiol. 258:E569-E575.

59. Exton, J. H., L. E. Mallette, L. S. Jefferson, E. H. Wong, N. Friedmen, T. B. Miller, Jr., and C. R. Park. 1970. The hormonal control of hepatic gluconeogenesis. Recent Prog. Horm. Res. 26:411-461.

60. Saccà, L., C. Vigorito, M. Cicala, G. Corso, and R. S. Sherwin. 1983. Role of gluconeogenesis in epinephrine-stimulated hepatic glucose production in humans. Am. J. Physiol. 245:E294-E302.

61. Randle, P. J., P. B. Garland, C. N. Hales, and E. A. Newsholme. 1963. The glucose-fatty acids cycle: its role in insulin sensitivity and the metabolic disturbances of diabetes mellitus. Lancet. i:785-789.

62. Randle, P. J., E. A. Newsholme, and P. B. Garland. 1964. Regulation of glucose uptake by muscle. 8. Effects of fatty acids, ketone bodies and pyruvate, and of alloxan-diabetes and starvation, on the uptake and metabolic fate of glucose in rat heart and diaphragm muscles. Biochem. J. 93:652-665.

63. De Fronzo, R. A. 1988. The triumvirate: $\beta$-cell, muscle, liver. A collusion responsible for NIDDM. Diabetes. 37:667-687.

64. Caprio, S., S. Amiel, W. V. Tamborlane, R. A. Gelfand, and R. S. Sherwin. 1990. Defective free-fatty acid and oxidative glucose metabolism in IDDM during hypoglycemia. Influence of glycemic control. Diabetes. 39:134-141.

65. Wolfe, R. R., and J. H. F. Shaw. 1986. Effect of epinephrine infusion and adrenergic blockade on glucose oxidation in conscious dogs. Metab. Clin. Exp. 35:673-678.

66. Bonadonna, R. C and R. A. De Fronzo 1991. Glucose metabolism in obesity and Type 2 diabetes. Diabete \& Metab. 17:112-135.

67. Thiebaud, D., R. A. De Fronzo, E. Jacot, A. Golay, K. Acheson, E. Maeder, E. Jequier, and J. P. Felber. 1982. Effect of long chain triglyceride infusion on glucose metabolism in man. Metab. Clin. Exp. 31:1128-1136.

68. Taskinen, M.-R., C. Bogardus, A. Kennedy, and B. V. Howard. 1985. Multiple disturbances of free fatty acid metabolism in non-insulin-dependent diabetes: effect of oral hypoglycemic therapy. J. Clin. Invest. 76:637-644.

69. Rizza, R., P. Cryer, M. Haymond, and J. Gerich. 1980. Adrenergic mechanisms for the effects of epinephrine on glucose production and clearance in man. J. Clin. Invest. 65:682-689.

70. Rizza, R. A., P. E. Cryer, M. W. Haymond, and J. E. Gerich. 1980. Adrenergic mechanisms of catecholamines action on glucose homeostatis in man. Metab. Clin. Exp. 29:1153-1163.

71. Blackard, W. G., and S. A. Heidingsfelder. 1968. Adrenergic receptor control mechanism for growth hormone secretion. J. Clin. Invest. 47:1407-1414.

72. Bolli, G. B., P. De Feo, M. G. Cartechini, G. Angeletti, F. Santeusanio, and P. Brunetti. 1982. Important role of adrenergic mechanisms in acute glucose counterregulation following insulin-induced hypoglycemia in type I diabetes: evidence for an effect mediated by beta-adrenoreceptors. Diabetes. 31:641-647.

73. Betley, S., and K. G. M. M. Alberti. 1989. Regulation of fatty acid and carbohydrate metabolism by insulin, growth hormone and tri-iodothyronine in hepatocyte cultures from normal and hypophysectomised rats. Biochem. J. 258:547-552.

74. Pontiroli, A. E., R. Lanzi, L. D. Monti, and G. Pozza. 1990. Effect of acipimox, a lipid lowering drug, on growth hormone (GH) response to GH-releasing hormone in normal subjects. J. Endocrinol. Invest. 13:539-542.

75. Clutter, W. E., R. A. Rizza, J. E. Gerich, and P. E. Cryer. 1988. Regulation of glucose metabolism by sympathochromoaffin catecholamines. Diabetes $M e$ tab. Rev. 4:1-15. 